\title{
2D Homologous Perovskites as Light-Absorbing Materials for Solar Cell Applications
}

\author{
Duyen H. Cao, ${ }^{\dagger}$ Constantinos C. Stoumpos, ${ }^{\dagger}$ Omar K. Farha, ${ }^{\dagger,}{ }^{\dagger}$ Joseph T. Hupp, ${ }^{\dagger}$
} and Mercouri G. Kanatzidis* ${ }^{\dagger}$

${ }^{\dagger}$ Department of Chemistry and Argonne-Northwestern Solar Energy Research (ANSER) Center, Northwestern University, 2145
Sheridan Road, Evanston, Illinois 60208, United States
${ }^{\ddagger}$ Department of Chemistry, Faculty of Science, King Abdulaziz University, Jeddah 21589, Saudi Arabia

Supporting Information

ABSTRACT: We report on the fabrication and properties of the semiconducting $2 \mathrm{D}\left(\mathrm{CH}_{3}\left(\mathrm{CH}_{2}\right)_{3} \mathrm{NH}_{3}\right)_{2}\left(\mathrm{CH}_{3} \mathrm{NH}_{3}\right)_{n-1} \mathrm{~Pb}_{n} \mathrm{I}_{3 n+1}(n=1$, 2,3 , and 4) perovskite thin films. The band gaps of the series decrease with increasing $n$ values, from $2.24 \mathrm{eV}\left(\mathrm{CH}_{3}\left(\mathrm{CH}_{2}\right)_{3} \mathrm{NH}_{3}\right)_{2} \mathrm{PbI}_{4}(n=1)$ to $1.52 \mathrm{eV} \mathrm{CH}_{3} \mathrm{NH}_{3} \mathrm{PbI}_{3}(n=\infty)$. The compounds exhibit strong light absorption in the visible region, accompanied by strong photoluminescence at room temperature, rendering them promising light absorbers for photovoltaic applications. Moreover, we find that thin films of the semi-2D perovskites display an ultrahigh surface coverage as a result of the unusual film self-assembly that orients the $\left[\mathrm{Pb}_{n} \mathrm{I}_{3 n+1}\right]^{-}$ layers perpendicular to the substrates. We have successfully implemented this $2 \mathrm{D}$ perovskite family in solid-state solar cells, and obtained an initial power conversion efficiency of $4.02 \%$, featuring an open-circuit voltage $\left(V_{\text {oc }}\right)$ of $929 \mathrm{mV}$ and a short-circuit current density

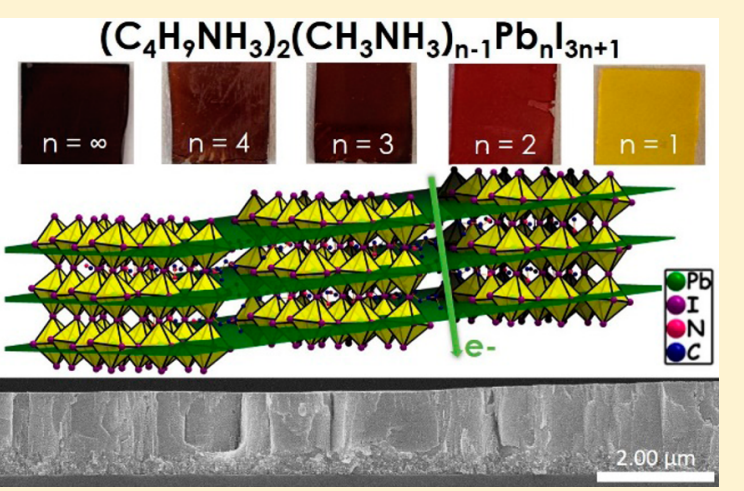
$\left(J_{s c}\right)$ of $9.42 \mathrm{~mA} / \mathrm{cm}^{2}$ from the $n=3$ compound. This result is even more encouraging considering that the device retains its performance after long exposure to a high-humidity environment. Overall, the homologous 2D halide perovskites define a promising class of stable and efficient light-absorbing materials for solid-state photovoltaics and other applications.

\section{INTRODUCTION}

The emergence of hybrid halide perovskite compounds, $\mathrm{AMX}_{3}$ $\left(\mathrm{A}=\mathrm{Cs}^{+}, \mathrm{CH}_{3} \mathrm{NH}_{3}{ }^{+}\right.$, or $\mathrm{HC}\left(\mathrm{NH}_{2}\right)_{2}{ }^{+} ; \mathrm{M}=\mathrm{Sn}^{2+}$ and $\mathrm{Pb}^{2+}$; and $\mathrm{X}=\mathrm{Cl}^{-}, \mathrm{Br}^{-}$, and $\mathrm{I}^{-}$), in solid-state solar cells has triggered a phenomenal advance in the photovoltaic efficiency in the last three years. $^{1-6}$ Perovskite compounds, in the form of $\mathrm{CH}_{3} \mathrm{NH}_{3} \mathrm{PbX}_{3}$, were originally employed as light-absorbing materials in liquid dye-sensitized solar cells by the Miyasaka group. ${ }^{7}$ However, they did not engender a lot of attention because of short device lifetime resulting from the fast dissolution of perovskites in the redox electrolyte solution. Three years later, we have witnessed the return of perovskitebased solar cells in a different fashion: solid-state., ${ }^{2,8}$ The photovoltaic performance race has been remarkable ever since, and an efficiency of $20.1 \%$ has been certified by NREL.,5 Among the light absorber candidates, 3D methylammonium (MA) lead iodide $\left(\mathrm{MAPbI}_{3}\right)$ is the most prominent choice owing to its outstanding properties for a solar cell absorber, including a high extinction coefficient, ${ }^{10}$ a medium band gap, ${ }^{11}$ a small exciton binding energy, and long exciton and charge diffusion lengths. ${ }^{12}$ From a commercialization point of view, the large-scale implementation of perovskite solar cells requires toxicity and stability issues to be resolved. Recently, works on tin-based perovskites have been reported, demonstrating a promising efficiency of ca. $5 \%$ for the $\mathrm{CH}_{3} \mathrm{NH}_{3} \mathrm{SnI}_{3-x} \mathrm{Br}_{x}$ system ${ }^{13,14}$ as well as in the mixed-metal $\mathrm{CH}_{3} \mathrm{NH}_{3} \mathrm{Sn}_{1-x} \mathrm{~Pb}_{x} \mathrm{I}_{3}$ system. ${ }^{15-17}$ The moisture instability of $\mathrm{MAPbI}_{3}$ however has been poorly addressed. Recently, Smith et al. reported the solar cell application of a layered $\left(\mathrm{PhC}_{2} \mathrm{H}_{5} \mathrm{NH}_{3}\right)_{2}\left(\mathrm{CH}_{3} \mathrm{NH}_{3}\right)_{2} \mathrm{~Pb}_{3} \mathrm{I}_{10}$ perovskite light absorber with enhanced moisture stability. ${ }^{18}$ From a fundamental point of view, efficient external luminescence is an indirect indication of accessing the highest possible open-circuit voltage, a major factor in the total power output aside from the short-circuit current and fill factor. ${ }^{19,20}$ The $2 \mathrm{D} \mathrm{A}_{2} \mathrm{MI}_{4}$-based perovskite compounds, where $\mathrm{M}$ is a divalent group $14^{21}$ or lanthanide ${ }^{22}$ metal, have been reported to display high photoluminescence (PL) at room temperature, and up until now, they have been employed in field-effect transistor (FET) $)^{23}$ and light-emitting diode (LED) devices. ${ }^{24,25}$ To move from the $3 \mathrm{D}$ to the $2 \mathrm{D}$ perovskites, the small $\mathrm{MA}^{+}$ cation is replaced by a much bulkier organic primary ammonium cation, thus confining the perovskite in two dimensions because of steric effects. With these considerations in mind, we turned our attention toward the multilayered perovskite compounds, $(\mathrm{A})_{2}\left(\mathrm{CH}_{3} \mathrm{NH}_{3}\right)_{n-1} M_{n} \mathrm{I}_{3 n+1}$, and their potential as light-absorbing materials, where the bulky

Received: April 13, 2015

Published: May 28, 2015 
ammonium (the spacer) and methylammonium (the "perovskitizer") cations are employed simultaneously.

2D multilayered halide perovskites take the generic structural formula of $(\mathrm{A})_{2}\left(\mathrm{CH}_{3} \mathrm{NH}_{3}\right)_{n-1} \mathrm{MX}_{3 n+1}(n$ is an integer), where $\mathrm{A}$ is a primary aliphatic or aromatic alkylammonium cation, $\mathrm{M}$ is a divalent metal, and $\mathrm{X}$ is a halide anion. The $2 \mathrm{D}$ network consists of inorganic layers of corner-sharing $\left[\mathrm{MX}_{6}\right]^{4-}$ octahedra confined between interdigitating bilayers of intercalated bulky alkylammonium cations. ${ }^{26}$ The unit layers are stacked together by a combination of Coulombic and hydrophobic forces to maintain the structure integrity. These $2 \mathrm{D}$ compounds could be regarded as natural multiple-quantumwell structures in which the semiconducting inorganic layers act as "wells" and the insulating organic layers act as "barriers". 24,27,28

In this article, we report on the fabrication and properties of thin films of the $2 \mathrm{D}$ lead iodide perovskite $\left(\mathrm{CH}_{3}\left(\mathrm{CH}_{2}\right)_{3} \mathrm{NH}_{3}\right)_{2}\left(\mathrm{CH}_{3} \mathrm{NH}_{3}\right)_{n-1} \mathrm{~Pb}_{n} \mathrm{I}_{3 n+1}$ series, which combines the structural features of the simple $2 \mathrm{D}(n=1)$ and the 3D $(n=\infty)$ perovskites. We then show that the thin films remarkably, grow with the $\left[\mathrm{Pb}_{n} \mathrm{I}_{3 n+1}\right]$ slabs perpendicular to the substrates and as a result can be used as the light-absorbing layer to fabricate functional solar cells. We establish here that unlike 3D $\mathrm{MAPbI}_{3}$ which requires more complex film fabrication methods to achieve high-quality films, $3,29,30$ the 2D analogues yield smooth, ultrahigh surface coverage films from a simple one-step spin-coating approach. In addition, 2D perovskite-based films are notably moisture-resistant. In this work, our best power conversion efficiency of $4.02 \%$ was obtained by using $\left(\mathrm{CH}_{3}\left(\mathrm{CH}_{2}\right)_{3} \mathrm{NH}_{3}\right)_{2}\left(\mathrm{CH}_{3} \mathrm{NH}_{3}\right)_{2} \mathrm{~Pb}_{3} \mathrm{I}_{10}$ as a light absorber, with an open-circuit voltage $\left(V_{\text {oc }}\right)$ of $929 \mathrm{mV}$ and a short-circuit current $\left(J_{\mathrm{sc}}\right)$ of $9.42 \mathrm{~mA} / \mathrm{cm}^{2}$.

\section{EXPERIMENTAL SECTION}

Materials. 2,2,7,7'-Tetrakis(N,N-di-p-methoxyphenylamine)9,9'spirobifluorene (spiro-OMeTAD) was purchased from Feiming Chemical Limited. Transparent titania $\left(\mathrm{TiO}_{2}\right)$ paste (Dyesol 18NR$\mathrm{T}$ ) was purchased from DyeSol. All other chemicals were purchased from Sigma-Aldrich. Unless otherwise stated, all were used as received. Methylammonium iodide (MAI) was synthesized by neutralizing equimolar amounts of a $57 \% \mathrm{w} / \mathrm{w}$ aqueous hydriodic acid (HI) and $40 \% \mathrm{w} / \mathrm{w}$ aqueous methylamine $\left(\mathrm{CH}_{3} \mathrm{NH}_{2}, \mathrm{pH} \sim 7\right)$. The white precipitate was collected by evaporation of the solvent using rotary evaporation at $60{ }^{\circ} \mathrm{C}$ under reduced pressure.

Synthesis. $\mathrm{PbO}$ powder was dissolved in a mixture of $57 \% \mathrm{w} / \mathrm{w}$ aqueous $\mathrm{HI}$ solution and $50 \%$ aqueous $\mathrm{H}_{3} \mathrm{PO}_{2}$ by heating to boiling under constant magnetic stirring for about 5 min, forming a brightyellow solution. Subsequent addition of solid $\mathrm{CH}_{3} \mathrm{NH}_{3} \mathrm{I}$ to the hot yellow solution initially caused the precipitation of a black powder that rapidly redissolved under stirring to afford a clear bright-yellow solution. $n-\mathrm{CH}_{3}\left(\mathrm{CH}_{2}\right)_{3} \mathrm{NH}_{2}$ was then added dropwise under vigorous stirring over a period of $1 \mathrm{~min}$ without any changes in the solution. The stirring was then discontinued, and the solution was left to cool to room temperature during which time deep-red rectangular-shaped plates started to crystallize. The precipitation was deemed to be complete after $\sim 2 \mathrm{~h}$. The crystals were isolated by suction filtration and thoroughly dried under reduced pressure.

Device Fabrication. FTO-coated glass $(1.5 \mathrm{~cm} \times 2.0 \mathrm{~cm}$, TEC 7, $2.2 \mathrm{~mm}$, Hartford Glass Co., Inc.) was patterned by etching away a 5 $\mathrm{mm}$ strip with zinc powder and $4 \mathrm{M} \mathrm{HCl}$. Then, substrates were cleaned by sonication in detergent, isopropanol, acetone, and dried under an air flow before use. A $20 \mathrm{~nm}$ thick $\mathrm{TiO}_{2}$ compact layer was deposited onto the substrates by atomic layer deposition (ALD; Savannah S300, Cambridge Nanotech Inc.) using titanium isopropoxide ( $0.15 \mathrm{~s}$ pulse time, $8 \mathrm{~s}$ exposure time, and $20 \mathrm{~s}$ purge time) and water ( $0.015 \mathrm{~s}$ pulse time, $8 \mathrm{~s}$ exposure time, $20 \mathrm{~s}$ purge time) as precursors. For planar structure, the ALDed $\mathrm{TiO}_{2}$ substrates were soaked in a $0.1 \mathrm{M}$ aqueous solution of $\mathrm{TiCl}_{4}$ for $30 \mathrm{~min}$ at $70{ }^{\circ} \mathrm{C}$, rinsed with deionized water, and dried at $500{ }^{\circ} \mathrm{C}$ for $20 \mathrm{~min}$. For sensitized structure, a mesoporous $\mathrm{TiO}_{2}$ layer composed of $20 \mathrm{~nm}$ particles was deposited on the ALD-treated $\mathrm{TiO}_{2}$ substrates by spincoating at $4000 \mathrm{rpm}$ for $30 \mathrm{~s}$ using a commercial $\mathrm{TiO}_{2}$ paste (Dyesol $18 \mathrm{NR}-\mathrm{T}$ ) diluted in anhydrous ethanol (2:7 weight ratio). Mesoporous $\mathrm{TiO}_{2}$ substrates were then gradually annealed by heating from room temperature to $500{ }^{\circ} \mathrm{C}\left(8^{\circ} \mathrm{C} / \mathrm{min}\right)$ for $15 \mathrm{~min}$, followed by post-treating in a $0.1 \mathrm{M}$ aqueous solution of $\mathrm{TiCl}_{4}$ for $30 \mathrm{~min}$ at $70^{\circ} \mathrm{C}$. The $\mathrm{TiO}_{2}$ substrates were finally rinsed with deionized water and dried at $500{ }^{\circ} \mathrm{C}$ for $20 \mathrm{~min}$. The light-absorbing layers were deposited by spin-coating $1.8 \mathrm{M} \mathrm{Pb}^{2+}$ perovskite precursor solutions at $3000 \mathrm{rpm}$ for $30 \mathrm{~s}$. The $1.8 \mathrm{M} \mathrm{Pb}^{2+}$ precursor solutions of $\mathrm{MAPbI}_{3}$, $(\mathrm{BA})_{2}(\mathrm{MA})_{n-1} \mathrm{~Pb}_{n} \mathrm{I}_{3 n+1} \quad(n=4,3,2$, and 1$)$ were prepared by dissolving the corresponding amount of perovskite powders in anhydrous dimethylformamide (DMF) solvent with stirring at $70{ }^{\circ} \mathrm{C}$ for $30 \mathrm{~min}$ prior to film deposition. $\mathrm{MAPbI}_{3}$ film was formed after annealing in air at $100{ }^{\circ} \mathrm{C}$ for $15 \mathrm{~min}$, whereas other $2 \mathrm{D}$ perovskite films were formed immediately after spin-coating at room temperature. The spiro-OMeTAD hole-transporting material (HTM) solution, comprised of $65.3 \mathrm{mM}$ spiro-OMeTAD, $9.1 \mathrm{mM}$ lithium bis(trifluoromethanesulfonyl)imide, and $93.8 \mathrm{mM}$ 4-tert-butylpyridine in chlorobenzene solvent, was then deposited on the perovskite layer by spin-coating at $4000 \mathrm{rpm}$ for $30 \mathrm{~s}$. Films were dried under vacuum overnight before completing the device fabrication process by thermal evaporating $80 \mathrm{~nm}$ of gold on top of the HTM layer.

\section{RESULTS AND DISCUSSION}

Film Fabrication and Film Growth Characteristics. The $2 \mathrm{D}\left(\mathrm{CH}_{3}\left(\mathrm{CH}_{2}\right)_{3} \mathrm{NH}_{3}\right)_{2}\left(\mathrm{CH}_{3} \mathrm{NH}_{3}\right)_{n-1} \mathrm{~Pb}_{n} \mathrm{I}_{3 n+1}$ family of perovskite compounds $(n=1-4)$ was synthesized from a stoichiometric reaction between $\mathrm{PbI}_{2}, \mathrm{MAI}$, and $n$-butylammine (BA). Structurally, the $2 \mathrm{D}$ perovskites are the product of slicing the 3D perovskite along the (110) plane, in such a way that some of the oriented MA cations are partially $(n=2,3$, and 4) or fully $(n=1)$ substituted by BA cations. ${ }^{24}$ More details of the synthesis and an in-depth study of crystal structures, physical, and optical properties of the $2 \mathrm{D}$ perovskite family will be reported separately.

The incorporation of perovskite light absorber into a functional solid-state solar device requires the transformation of perovskite powder materials into thin films. In this work, all perovskite films were fabricated by a one-step deposition method, by means of spin-coating the DMF precursor solutions of perovskite on mesoporous $\mathrm{TiO}_{2}$ substrates. The well-studied $\mathrm{MAPbI}_{3-x} \mathrm{Cl}_{x}$ film was also prepared for comparison purposes. ${ }^{2}$ To fabricate $\mathrm{MAPbI}_{3-x} \mathrm{Cl}_{x}$ film, the precursor solution was prepared by mixing a 3:1 molar ratio of $\mathrm{MAI}$ and $\mathrm{PbCl}_{2}$ in DMF. Deposition of the $\mathrm{MAPbI}_{3}$ film by the one-step approach has been shown to produce low-quality films that suffer from low surface coverage and large, nonuniform crystal size, resulting in low conversion efficiency. Therefore, many different approaches of film deposition have been examined to improve the film quality, including high-vacuum vapor deposition, sequential deposition, vapor-assisted deposition, solvent engineering, etc. . $93,30,4^{2}$ Conversely, in this work we observe highquality $2 \mathrm{D}$ perovskite films can be easily formed using the onestep method. The 2D perovskites self-assemble to form welldefined films on the substrates with nearly perfect surface coverage and a fine texture. The growth of the films is clearly driven by the $2 \mathrm{D}$ nature of the compounds forming highly oriented crystals with only a few grain boundaries. Interestingly, the $2 \mathrm{D}$ films are readily formed immediately after the spincoating process without requiring annealing steps, demonstrat- 
ing a facile preparatory method and rendering it compatible with flexible substrates.

The thin films of $(\mathrm{BA})_{2}(\mathrm{MA})_{n-1} \mathrm{~Pb}_{n} \mathrm{I}_{3 n+1}$ perovskites show a highly remarkable tendency when the orientation of the structure on the substrate is considered (Figures 1 and 2).

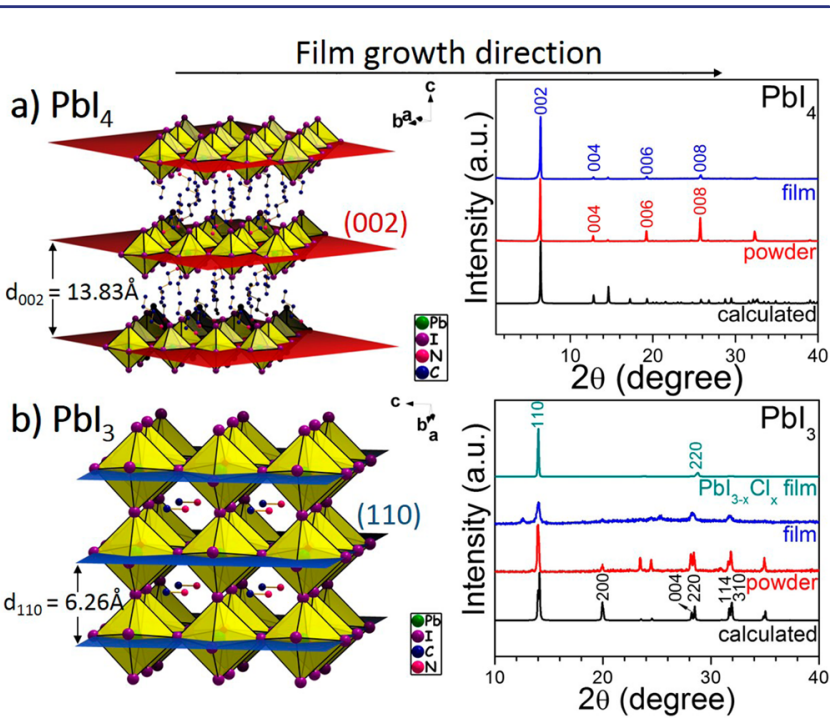

Figure 1. XRD of thin films vs bulk materials of (a) $\mathrm{BA}_{2} \mathrm{PbI}_{4}$ and (b) $\mathrm{MAPbI}_{3}$ perovskites, with the illustration of their respective diffraction planes. In b, films of $\mathrm{MAPbI}_{3}$ correspond to the unique and ideal case of perfect orientation obtained from the 3D $\mathrm{MAPbI}_{3-x} \mathrm{Cl}_{x}$ system.
Generally, the orientation of 2D materials on flat substrates strongly favors growth where the layers orient parallel to the substrate, a trend that has also been observed in the case of single-layer halide perovskites. ${ }^{31}$ In the case of $(\mathrm{BA})_{2}(\mathrm{MA})_{n-1} \mathrm{~Pb}_{n} \mathrm{I}_{3 n+1}$, this trend appears to be true only for the $n=1$ compound, where preferential growth along the (110) direction occurs, thus exclusively revealing the (001) reflections. As soon as the layers become thicker $(n>1)$, a competition arises between the BA ions, which try to confine the growth within the planar layer, and the MA ions, which try to expand the perovskite growth outside the layer. Already for the $n=2$ compound, the $(0 k 0)$ reflections are "contaminated" with the (111) and (202) reflections, which reveal the vertical growth of the compound with respect to the substrate plane. (Note that the $(0 k 0)$ reflections for $n=2-4$ correspond to the $(00 l)$ reflection for $n=1$ and $\infty$.) The $n=3$ and 4 compounds continue the trend by showing exclusively the (111) and (202) reflections and lacking $(0 k 0)$ reflections, clearly indicating the vertical growth of the perovskite compounds. This effect becomes even more pronounced when one compares it with the preferential growth of the bulk $(\mathrm{BA})_{2}(\mathrm{MA})_{n-1} \mathrm{~Pb}_{n} \mathrm{I}_{3 n+1}$ compounds (Figures 1 and 2). These appear to follow the standard norms (crystallizing along the ( $\mathrm{h} 0 \mathrm{l}$ ) plane), thereby showing only the $(0 k 0)$ reflections. We reason that the (111) reflection dominates the diffraction patterns because the (101) reflection is not allowed $(h=2 n$ and $h, l=2 n$ reflection conditions); therefore, the closest plane describing the vertical growth becomes the (111) plane.

\section{Film growth direction}
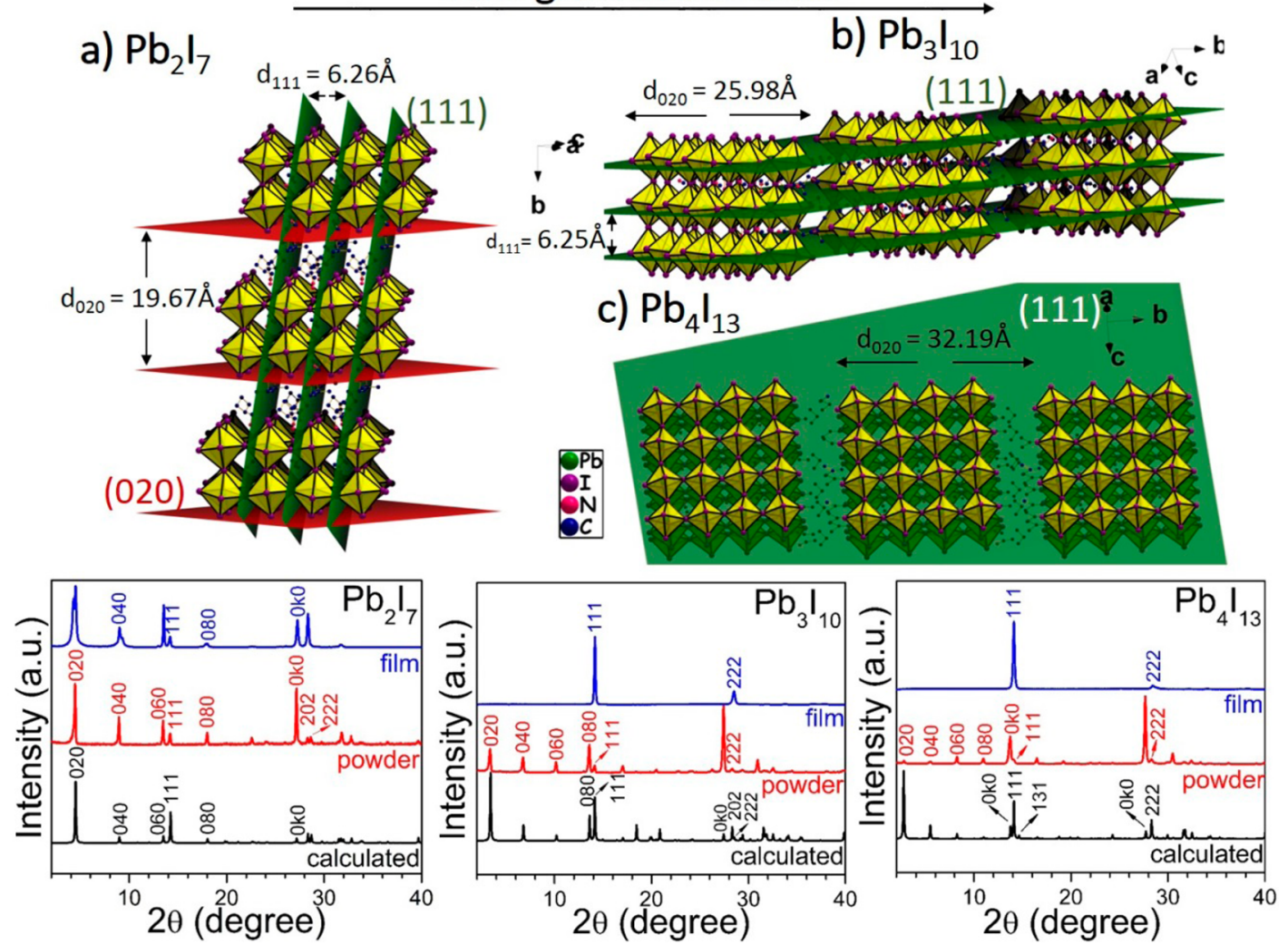

Figure 2. XRDs of thin films vs bulk materials of (a) $(\mathrm{BA})_{2}(\mathrm{MA}) \mathrm{Pb}_{2} \mathrm{I}_{7},(\mathrm{~b})(\mathrm{BA})_{2}(\mathrm{MA})_{2} \mathrm{~Pb}_{3} \mathrm{I}_{10}$, and (c) $(\mathrm{BA})_{2}(\mathrm{MA})_{3} \mathrm{~Pb} \mathrm{I}_{13}$ perovskites, with the illustration of their respective diffraction planes. Note that the Miller indices are different from those of $(\mathrm{BA})_{2} \mathrm{PbI}_{4}$ and $\mathrm{MAPbI}_{3}$ because of the different assignment of the orthogonal unit cell axes. 
The extremely well oriented $(\mathrm{BA})_{2}(\mathrm{MA})_{n-1} \mathrm{~Pb}_{n} \mathrm{I}_{3 n+1}$ perovskite films are already superior to $\mathrm{MAPbI}_{3}$ films deposited by the crude one-step method, and their quality is already comparable to the best-oriented $\mathrm{MAPbI}_{3}$ films obtained by means of the superior "mixed-halide" $\mathrm{MAPbI}_{3-x} \mathrm{Cl}_{x}$ method (Figure $1 \mathrm{~b}) .^{2}$ The successful vertical crystal growth of the $2 \mathrm{D}$ perovskites on the substrate is further confirmed by the scanning electron microscopy (SEM) images, exemplified in the form of $\mathrm{Pb}_{3} \mathrm{I}_{10}$ films. Figure $3 \mathrm{~d}$ shows extremely well-



Figure 3. ( $a$ and $b$ ) Top surface and ( $c$ and $d$ ) cross-sectional SEM images of $\mathrm{MAPbI}_{3}$ and $(\mathrm{BA})_{2}(\mathrm{MA})_{2} \mathrm{~Pb}_{3} \mathrm{I}_{10}$ on $\mathrm{TiO}_{2}$ films.

packed, vertically oriented crystallites displaying excellent surface coverage. Vertical growth is highly desirable in photovoltaic devices because it facilitates charge transport along the $\mathrm{Pb}-\mathrm{I}-\mathrm{Pb}$ pathway to the electron- and holeaccepting contacts. Additionally, the evolution of continuous crystallites with few crystal boundaries promises significant improvement in the carrier transport mobility.

Another favorable property of the 2D perovskite films that also benefits their potential technological exploitation is their extremely high moisture stability. As an example, a film of $\mathrm{MAPbI}_{3}$ gradually decomposed to yellow $\mathrm{PbI}_{2}$ after a short time in moist atmosphere because of the gradual loss of the $\mathrm{MA}^{+}$ cation (Figure $4 \mathrm{~b}$ ). However, a film of $(\mathrm{BA})_{2}(\mathrm{MA})_{2} \mathrm{~Pb}_{3} \mathrm{I}_{10}$ remained unchanged after 2 months exposure under a $40 \%$ humidity condition. The stability of the film was additionally confirmed by XRD (Figure 4a), in which no $\mathrm{PbI}_{2}$ peak was observed in the 2 month old $(\mathrm{BA})_{2}(\mathrm{MA})_{2} \mathrm{~Pb}_{3} \mathrm{I}_{10}$ film. The moisture-resistant property of the $2 \mathrm{D}$ perovskites may be

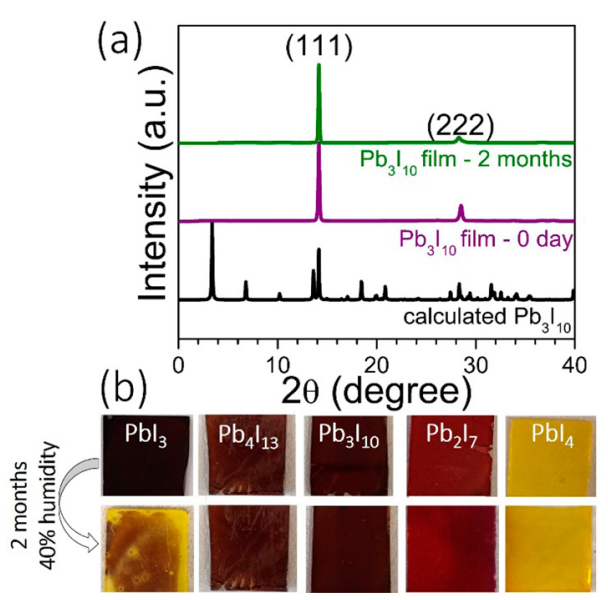

Figure 4. (a) XRDs of fresh and aged (2 months) (BA) $)_{2}(\mathrm{MA})_{2} \mathrm{~Pb}_{3} \mathrm{I}_{10}$ film. (b) Images of five different perovskite films before and after exposure to humidity. attributed to the hydrophobicity of the long BA cation chain and the highly oriented and dense nature of the perovskite films, which prevent direct contact of adventitious water with the perovskite.

Optical Properties. For convenience, in the present and forthcoming sections, we will abbreviate $\mathrm{MAPbI}_{3}$ as $\mathrm{PbI}_{3}$, and the $2 \mathrm{D}$ series as $\mathrm{Pb}_{4} \mathrm{I}_{13}, \mathrm{~Pb}_{3} \mathrm{I}_{10}, \mathrm{~Pb}_{2} \mathrm{I}_{7}$, and $\mathrm{PbI}_{4}$ when $n$ is equal to $4,3,2$, and 1, respectively. Previously, in our work on twostep sequentially deposited films of $\mathrm{PbI}_{3}$, we observed some unusually broad absorption edges lying between the band edges of $\mathrm{PbI}_{2}(2.4 \mathrm{eV})$ and $\mathrm{PbI}_{3}(1.5 \mathrm{eV}) .^{32}$ We speculated these absorption characteristics were due to incomplete conversion of $\mathrm{PbI}_{2}$, leading to the formation of intermediate layered compounds that were stabilized by surface effects on the thin films. We investigated the optical properties of the series in both bulk and thin film samples. The optical band gaps $\left(E_{\mathrm{g}}\right)$ in the $(\mathrm{BA})_{2}(\mathrm{MA})_{n-1} \mathrm{~Pb}_{n} \mathrm{I}_{3 n+1}$ series increase with decreased thickness of the inorganic slabs from $1.52 \mathrm{eV}(n=\infty)$ to $2.24 \mathrm{eV}(n=1)$ because of quantum confinement effects from the dimensional reduction of the perovskite chromophore. ${ }^{33-35}$ In addition to the primary absorption edge, we observed another peak above the absorption edge region appearing in the $2 \mathrm{D}$ perovskites. The intensity of the second peak is strongest for the $n=1$ compound and progressively subsides as the number of the inorganic slabs increases; it practically disappears for the $n=4$ compound (Figure 5a). This secondary absorption is attributed to a long-lived excitonic state trapped in the strong electrostatic field generated by the localized positively charged $\mathrm{BA}$ ions around the negatively charged (MA) ${ }_{n-1} \mathrm{~Pb}_{n} \mathrm{I}_{3 n+1}$ layers. ${ }^{28}$ This local electric field provides sufficient chargescreening that inhibits the long-range separation of the photogenerated electron-hole pair, thus increasing its recombination probability. The excitonic binding energies of the layered perovskite series are thus expected to decrease with increasing $n$ (from 1 to $\infty$ ). The same behavior is also observed in the absorption spectra of the spin-coated $\mathrm{TiO}_{2}$-perovskite films of the compounds (Figure $5 \mathrm{~b}$ ), thus further validating the successful deposition of the target compound onto the substrate. Interestingly, the absorption spectra of the pure compounds are in good agreement with those of the intermediate absorption spectra observed in the two-stepdeposited $\mathrm{MAPbI}_{3}{ }^{32}$ an observation that hints toward the possibility of the formation of layered-like intermediates during the formation of the $3 \mathrm{D}$ perovskite films that are stabilized by the $\mathrm{TiO}_{2}$ surfaces.

As is well-demonstrated, thin films of both the $2 \mathrm{D} \mathrm{PbI}_{4}$ and 3D $\mathrm{PbI}_{3}$ compounds display $\mathrm{PL}$ at room temperature (RT). ${ }^{24,36,37}$ We have sought to confirm this property by performing PL measurements on the $(\mathrm{BA})_{2}(\mathrm{MA})_{n-1} \mathrm{~Pb}_{n} \mathrm{I}_{3 n+1}$ homologous perovskite series on films deposited onto glass substrates. Indeed, we observe RT PL from all 2D perovskites as shown in Figure 5c. The PL spectra of all four 2D compounds and the 3D analogue have distinct features that are fully consistent with the experimentally determined optical band gaps. A very strong PL emission is observed for the $n=1$ compound; the emission wavelength corresponds to the highenergy absorption peak (bound exciton), and it lies above the ground state of the band gap. Interestingly, when additional slabs are introduced (increasing $n$ ), the PL emission energy shifts in each case according to the low-energy absorption peak (free exciton) and applies to the $n=2,3$, and 4 compounds. The efficient external luminescence observed in the compounds is a highly desirable property for photovoltaic applications 

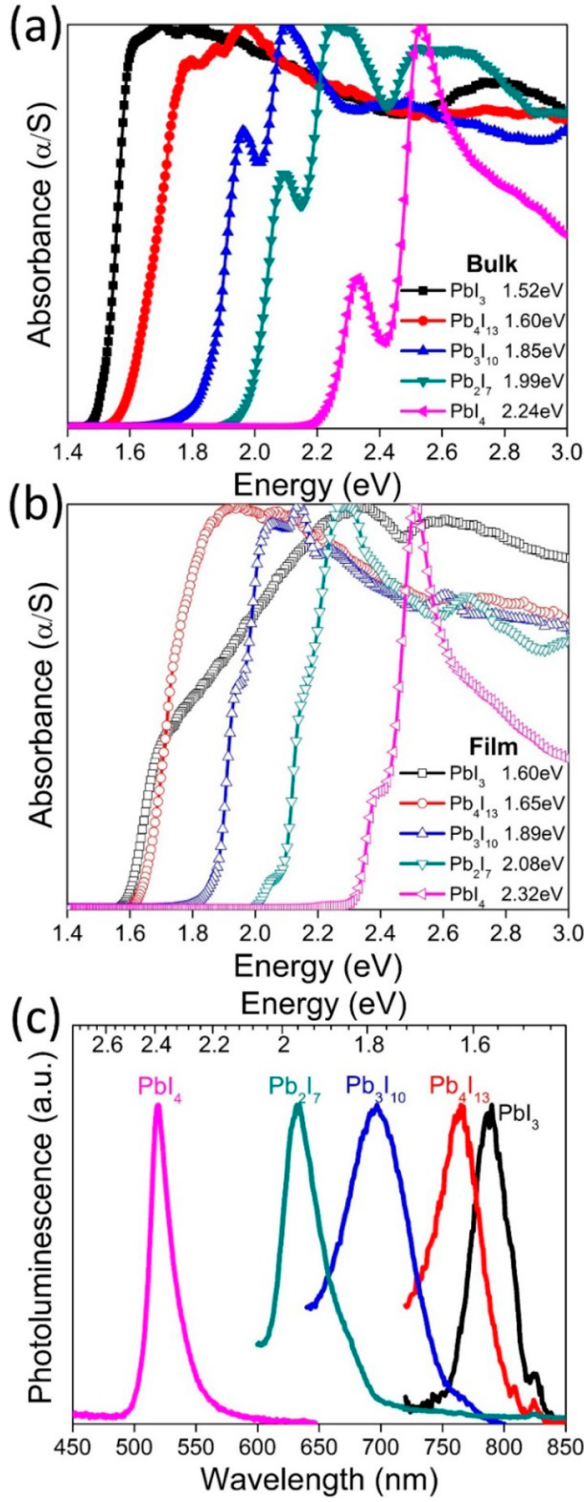

Figure 5. Optical band gaps of (a) bulk, (b) spin-coated $\mathrm{TiO}_{2}-$ perovskite thin films, and (c) PL spectra of spin-coated glassperovskite thin films of the $\mathrm{MAPbI}_{3}$ and $(\mathrm{BA})_{2}(\mathrm{MA})_{n-1} \mathrm{~Pb}_{n} \mathrm{I}_{3 n+1}$ compounds.

because it is an indirect indication of efficient carrier generation, thus granting access to the highest possible open-circuit voltage. $^{19}$

Device Fabrication and Photovoltaic Performance. As stated in the previous section, the properties of the $(\mathrm{BA})_{2}(\mathrm{MA})_{n-1} \mathrm{~Pb}_{n} \mathrm{I}_{3 n+1}$ perovskite films show unique film growth characteristics that offer tremendous potential for successful implementation in solar cells. We thus proceeded to assemble and characterize photovoltaic devices. Initial attempts yielded a promising, high $V_{\text {oc }}$ from devices of the semiconducting $2 \mathrm{D} \mathrm{Pb} \mathrm{P}_{10}$ compound. Hence, we followed up by exploring two different aspects: (i) changing the device structure from planar $\left(\mathrm{TiO}_{2}\right.$ compact layer only) to sensitized (250-1100 nm mesoporous $\mathrm{TiO}_{2}$ ) and (ii) changing the perovskite precursor concentration $(0.9,1.8,2.7$, and $3.6 \mathrm{M}$, based on the total $\mathrm{Pb}^{2+}$ content). The photovoltaic responses of all fabricated devices can be found in Supporting Information section S7. The side view of typical $\mathrm{TiO}_{2}$-deposited $2 \mathrm{D}$ perovskite films prior to the HTM deposition step are shown in Figure 6.

Our champion first-generation 2D device was obtained from the $\mathrm{Pb}_{3} \mathrm{I}_{10}$ light absorber in combination with a $350 \mathrm{~nm} \mathrm{TiO}$ mesoporous film and $1.8 \mathrm{M}$ perovskite concentration. (See Figure S4 for cross-sectional SEM image of a complete device.) Under AM 1.5G solar illumination, the photogenerated $V_{\text {oc }}$ was $929 \mathrm{mV}$, and $J_{\mathrm{sc}}$ was $9.43 \mathrm{~mA} / \mathrm{cm}^{2}$, ultimately yielding a conversion efficiency $\eta$ of $4.02 \%$ as shown in Figure 7 and

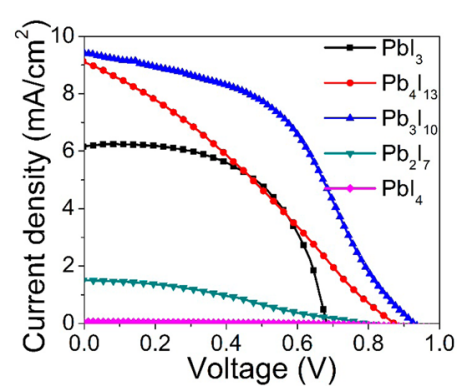

Figure 7. $J-V$ curves of sensitized lead iodide perovskite-based solar cells.

Table 1. Photovoltaic Performances of Sensitized Lead Iodide Perovskite-Based Solar Cells

\begin{tabular}{lcccc}
\multicolumn{1}{c}{ device } & $J_{\text {sc }}\left(\mathrm{mA} / \mathrm{cm}^{2}\right)$ & $V_{\text {oc }}(\mathrm{mV})$ & $\mathrm{FF}(\%)$ & efficiency (\%) \\
$\mathrm{MAPbI}_{3}$ & 6.15 & 684 & 57 & 2.41 \\
$(\mathrm{BA})_{2}(\mathrm{MA})_{3} \mathrm{~Pb}_{4} \mathrm{I}_{13}$ & 9.09 & 872 & 30 & 2.39 \\
$(\mathrm{BA})_{2}(\mathrm{MA})_{2} \mathrm{~Pb}_{3} \mathrm{I}_{10}$ & 9.42 & 929 & 46 & 4.02 \\
$(\mathrm{BA})_{2}(\mathrm{MA}) \mathrm{Pb}_{2} \mathrm{I}_{7}$ & 1.50 & 800 & 33 & 0.39 \\
$(\mathrm{BA})_{2} \mathrm{PbI}_{4}$ & 0.06 & 580 & 29 & 0.01 \\
\hline
\end{tabular}

Table 1. The performance of the $\mathrm{PbI}_{3}$ device, prepared under identical conditions, was lower than that of the current champion device. ${ }^{5}$ We attribute this difference mainly to the high concentration of $\mathrm{PbI}_{3}$ precursor and the one-step
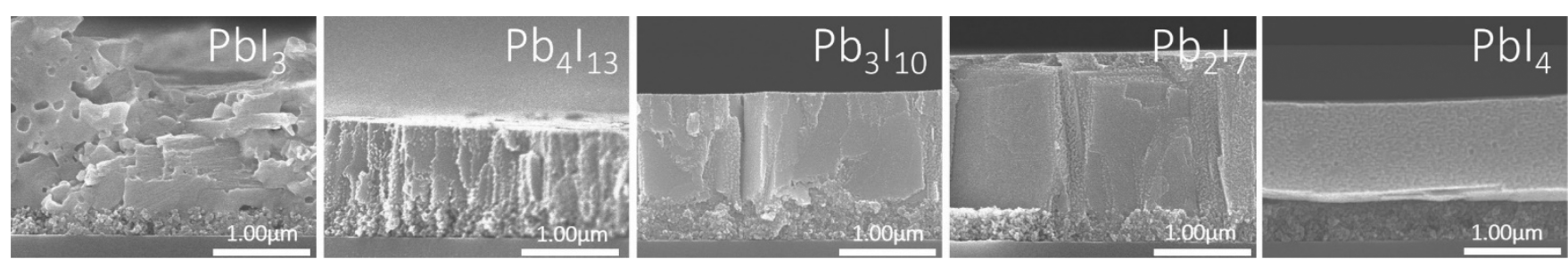

Figure 6. Cross-sectional SEM images of $\mathrm{TiO}_{2}$ - perovskite films prepared from $1.8 \mathrm{M} \mathrm{Pb}^{2+}$ precursors, showing preferentially oriented film growth of $2 \mathrm{D}$ perovskite compounds. 
deposition method. We intentionally used this method to keep the device fabrication process constant between the $3 \mathrm{D}$ and $2 \mathrm{D}$ materials in order to properly evaluate the resulting devices. Our approaches for the fabrication of high-efficiency $\mathrm{PbI}_{3}$ devices have been reported elsewhere. ${ }^{32,38}$ The $J_{\text {sc }}$ obtained from $\mathrm{Pb}_{4} \mathrm{I}_{13}$ is similar to that of $\mathrm{Pb}_{3} \mathrm{I}_{10}$, but the $V_{\text {oc }}$ and the FF are significantly lower, resulting in a substantially lower conversion efficiency. With $\mathrm{Pb}_{4} \mathrm{I}_{13}$ having a lower $E_{\mathrm{g}}$ than $\mathrm{Pb}_{3} \mathrm{I}_{10}$, we anticipated that the $\mathrm{Pb}_{4} \mathrm{I}_{13}$-based device would attain a higher $J_{\mathrm{sc}}$. However, other factors may influence the overall device performance. For instance, Figure 6 shows a thinner $\mathrm{Pb}_{4} \mathrm{I}_{13}$ film formed compared to that formed by $\mathrm{Pb}_{3} \mathrm{I}_{10}$, even though films were prepared from the same concentration of precursor solution $\left(1.8 \mathrm{M} \mathrm{Pb}^{2+}\right)$. One possible explanation for this is that the smaller amount of light-absorbing material absorbs less light and generates less photocurrent, yielding a lower $J_{\mathrm{sc}}$. The other two compounds of the $2 \mathrm{D}$ series, $\mathrm{Pb}_{2} \mathrm{I}_{7}$ and $\mathrm{PbI}_{4}$, produce significantly less current than those of the higher 2D members with thicker inorganic slabs, plausibly because of their much higher optical band gaps and their less favorable film growth characteristics for charge transport. Specifically, $\mathrm{Pb}_{2} \mathrm{I}_{7}$ film grows in both $(0 k 0)$ and $(111)$ orientations, and $\mathrm{PbI}_{4}$ film grows parallel to its substrate, along the $(00 k)$ plane.

To gain better insight into the charge transport dynamics in the $2 \mathrm{D}$ perovskite devices, we determined the position of the valence band maxima (VBM) of all five $(\mathrm{BA})_{2}(\mathrm{MA})_{n-1} \mathrm{~Pb}_{n} \mathrm{I}_{3 n+1}$ perovskite compounds, via ultraviolet photoelectron spectroscopy (UPS). The conduction band (CB) minima were determined by subtracting the VBM from the corresponding $E_{\mathrm{g}}$. As can be seen in Figure 8, the VBM increases with

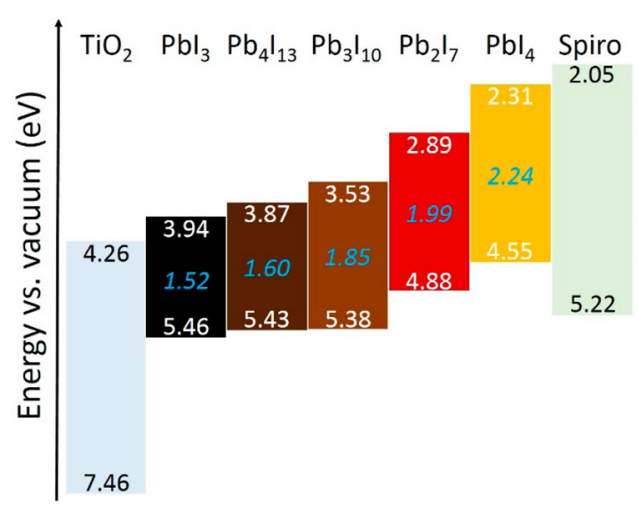

Figure 8. Comparative band energy diagram of the $(\mathrm{BA})_{2}(\mathrm{MA})_{n-1} \mathrm{~Pb}_{n} \mathrm{I}_{3 n+1}$ perovskite compounds.

decreased dimensionality, from $\mathrm{PbI}_{3}(5.46 \mathrm{eV})$ to $\mathrm{PbI}_{4}(4.55$ $\mathrm{eV})$. The $\mathrm{CB}$ energy edges of all five perovskite compounds are higher than that of the $\mathrm{TiO}_{2}$ electron acceptor, which theoretically would allow electron injection from the lightabsorbing materials to $\mathrm{TiO}_{2}$ unless the charge recombination process happens at a faster rate. Although it is favorable for holes generated from $\mathrm{PbI}_{3}, \mathrm{~Pb}_{4} \mathrm{I}_{13}$, and $\mathrm{Pb}_{3} \mathrm{I}_{10}$ to hop into the spiro-OMeTAD hole-transporter, this step is inhibited with $\mathrm{Pb}_{2} \mathrm{I}_{7}$ and $\mathrm{PbI}_{4}$ because their VBM energy levels are higher than the HOMO level of spiro-OMeTAD. Therefore, the probability of the photogenerated electrons and holes recombining is higher in $\mathrm{Pb}_{2} \mathrm{I}_{7}$ and $\mathrm{PbI}_{4}$, which essentially lowers their photocurrent densities.

The routine observation of $V_{\mathrm{oc}}$ in excess of $900 \mathrm{mV}$ from cells based on the semi-2D $\mathrm{Pb}_{3} \mathrm{I}_{10}$ compound ( $200 \mathrm{mV}$ higher than those based on $\mathrm{PbI}_{3}$ ) seems particularly promising and could bode well for incorporation of the material in more complex structures, e.g., the top cell in a tandem solar cell. ${ }^{39,40}$ For $\mathrm{PbI}_{3}$-based solar cells, it has been shown that photogenerated excitons dissociate into free charges within the perovskite, regardless of whether electron- and/or holeaccepting layers are present. ${ }^{12,41}$ The observed $V_{\text {oc }}$ of the $\mathrm{Pb}_{3} \mathrm{I}_{10}$-based device is in line with what might be anticipated from the HTM HOMO and the $\mathrm{TiO}_{2} \mathrm{CB}$ edge energy, but it is only half that of the $\mathrm{Pb}_{3} \mathrm{I}_{10}$ bandgap. Replacement of the electron- and hole-accepting materials with ones much better matched to the $\mathrm{Pb}_{3} \mathrm{I}_{10}$ (or $\mathrm{Pb}_{4} \mathrm{I}_{13}$ ) VB and $\mathrm{CB}$ edge energies may yield substantially higher open-circuit photovoltages without undue penalties for short-circuit photocurrents. This is under investigation in our laboratory, and the findings will be reported separately.

With $\mathrm{Pb}_{3} \mathrm{I}_{10}$ demonstrating the best conversion efficiency, we further investigated the photoresponses of this compound. In particular, we investigated the performances of cells containing planar versus nanoparticulate electron-accepting layers device structures (for simplicity, we will refer to the latter as sensitized devices). We prepared planar devices with increasing thicknesses of the perovskite light-absorber layer by means of increasing the precursor concentration from 0.9 to $3.6 \mathrm{M}$ of $\mathrm{Pb}^{2+}$. As can be seen in Figure 9, the $J_{\mathrm{sc}}$ of planar devices are

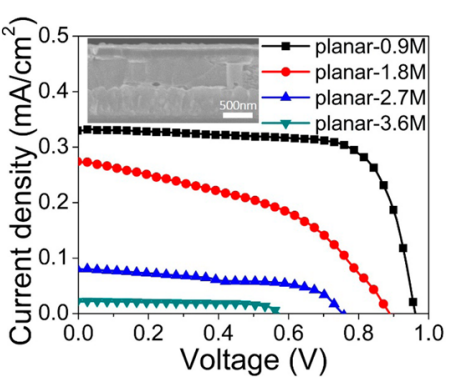

Figure 9. $J-V$ curves of planar $(\mathrm{BA})_{2}(\mathrm{MA})_{2} \mathrm{~Pb}_{3} \mathrm{I}_{10}$-based devices.

very low despite the presence of a thick perovskite layer $(\sim 600$ $\mathrm{nm}$ for $1.8 \mathrm{M}$ ). In addition, both $J_{\mathrm{sc}}$ and $V_{\mathrm{oc}}$ gradually decrease when the light-absorber layer gets thicker. This observation implies that the overwhelming majority of photogenerated electrons are unable to diffuse through the thick perovskite layer to reach the $\mathrm{TiO}_{2}$ electron-acceptor interface. Conversely, when a mesoporous $\mathrm{TiO}_{2}$ layer is introduced, $J_{\text {sc }}$ is tremendously enhanced. This is an indication that the charge (electron) diffusion length of $\mathrm{Pb}_{3} \mathrm{I}_{10}$ is likely shorter than that of $\mathrm{PbI}_{3}$ because the planar device structure of $\mathrm{PbI}_{3}$ has been successfully implemented elsewhere. ${ }^{30}$ Nonetheless, the planar device structure offers significantly better FF, suggesting that the semiconducting $2 \mathrm{D} \quad \mathrm{Pb}_{3} \mathrm{I}_{10}$ material itself possesses high carrier mobility. It is noticeable that the fill factor (FF) of $2 \mathrm{D}$ sensitized-devices is somewhat lower than those of $2 \mathrm{D}$ planar and $3 \mathrm{D}$ devices. This low FF value is an indication of high series resistance $\left(R_{\mathrm{s}}\right)$, which can be attributed to the suboptimal crystallinity of perovskites inside the mesoporous $\mathrm{TiO}_{2}$ layer and the charge-transport resistance at the interface of mesoporous $\mathrm{TiO}_{2}$ and perovskite. Predictably, the low FF can be overcome by replacing the current charge-selective contacts with the more compatible candidates.

It is remarkable that the sensitized device structure of $\mathrm{Pb}_{3} \mathrm{I}_{10}$ functions well despite having a thick $(\sim 1000 \mathrm{~nm})$ perovskite 
capping layer on top of the $\mathrm{TiO}_{2}$ mesoporous layer. It is certain that the light absorber infiltrated in the mesoporous $\mathrm{TiO}_{2}$ contributes majorly to the converted $J_{\mathrm{sc}}$. However, most of the photogenerated electrons in the perovskite capping layer likely recombine before reaching the $\mathrm{TiO}_{2}$ layer, as suggested by the fact that the planar device structure offers a very low $J_{s c}$. Therefore, photogenerated holes must be capable of diffusing through the thick perovskite capping layer to reach the selective HTM spiro-OMeTAD because the device is still functional. In this regard, the preferential growth of $\mathrm{Pb}_{3} \mathrm{I}_{10}$ layers perpendicular to the substrate is likely beneficial for efficient hole diffusion.

Having established that $\mathrm{Pb}_{3} \mathrm{I}_{10}$ requires the mesoporous $\mathrm{TiO}_{2}$ electron-carrier contact to produce high $J_{s c}$ we studied the photovoltage responses of devices with and without HTM to see if the hole-carrier contact is beneficial for device performance. As shown in Figure 10a, $V_{\text {oc }}$ decreases by 130
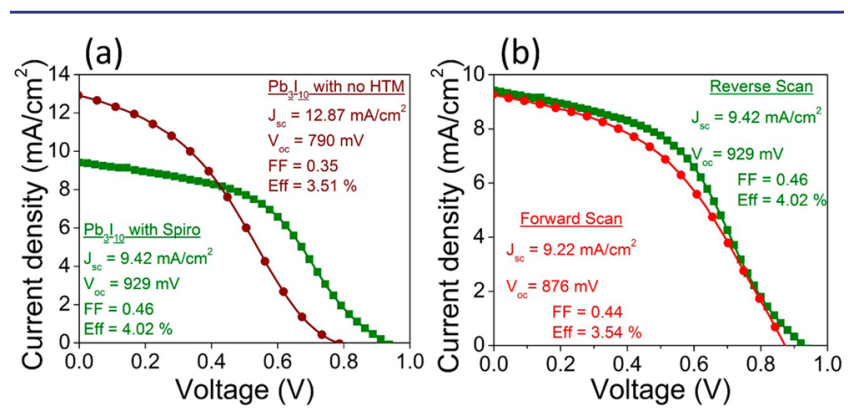

Figure 10. Photovoltaic responses of sensitized $(\mathrm{BA})_{2}(\mathrm{MA})_{2} \mathrm{~Pb}_{3} \mathrm{I}_{10^{-}}$ based devices (a) with and without hole transporter and (b) under reverse and forward scan directions.

$\mathrm{mV}$ when spiro-OMeTAD is eliminated. Such a voltage loss value is about the mismatch between the energy levels of $\mathrm{Au}$ and spiro-OMeTAD. Strikingly, the $J_{\mathrm{sc}}$ of the HTM-free device is about $3 \mathrm{~mA} / \mathrm{cm}^{2}$ higher compared to that of the HTMpresent device. When HTM is absent, charge recombination processes between $\mathrm{TiO}_{2}$ and HTM and/or perovskite and HTM are eliminated, increasing the survival time of the photogenerated electron population and yielding a higher $J_{\mathrm{sc}}$.

Recently, the anomalous hysteresis and ferroelectric behavior for $\mathrm{PbI}_{3}$-based solar cells has been investigated by several groups. ${ }^{42-46}$ Briefly, when the bias is applied from short-circuit to open-circuit direction (forward scan), charge is trapped at the electron-acceptor interface as capacitive current and cannot be fully discharged to the external circuit, showing an underestimated $J_{\mathrm{sc}}$. Conversely, if the bias is applied from open-circuit to short-circuit (reverse scan), then the capacitive charge accumulated will be discharged to the external circuit in combination with photogenerated current, showing the real $J_{\text {sc }}{ }^{47}$ This ferroelectric property of perovskites might lead to greater than band gap photovoltages as has been demonstrated in multiferroic oxide solar cells. ${ }^{48}$ Herein, hysteresis was also observed to a small degree in our sensitized $\mathrm{Pb}_{3} \mathrm{I}_{10}$ device, which results in a small drop in FF and $V_{\text {oc }}$ (Figure 10b).

\section{CONCLUDING REMARKS}

We have demonstrated the facile fabrication of the $2 \mathrm{D}$ $(\mathrm{BA})_{2}(\mathrm{MA})_{n-1} \mathrm{~Pb}_{n} \mathrm{I}_{3 n+1}(n=4,3,2,1)$ perovskite thin films along with the detailed characterization of their film growth behaviors, optical, and electronic properties. The $n=1$ and 2 members of the $2 \mathrm{D}$ perovskite family display strong photo- luminescence at room temperature, pointing to their potential for use in light-emitting diodes. Films of $2 \mathrm{D}$ compounds are formed in a self-assembly fashion with preferentially oriented growth perpendicular to the substrate, favoring charge transport and providing essential access to ultrasmooth and high-surfacecoverage thin films. An additional benefit of using large organic cations in the $2 \mathrm{D}$ films is moisture resistance that is greatly enhanced compared to that of their 3D $\mathrm{MAPbI}_{3}$ analogue, making them more attractive for large-scale industrial implementation. Our best first-generation $2 \mathrm{D}$ device is obtained from the semi-2D $(\mathrm{BA})_{2}(\mathrm{MA})_{2} \mathrm{~Pb}_{3} \mathrm{I}_{10}$ light absorber under the sensitized device structure, which yields a solar-toelectricity conversion efficiency of $4.02 \%$. Work in progress is directed toward improving charge diffusion length of the perovskite light-absorbing materials via synthesis routes as well as device parameters such as the fill factor and open-circuit photovoltage loss by exploring more compatible electron- and hole-carrier layers in both planar and sensitized device structures.

\section{ASSOCIATED CONTENT}

\section{Supporting Information}

Detailed material and device characterization, additional SEM images of perovskite crystals and films, work function of perovskite cold-pressed pellets, and additional photovoltaic data of $(\mathrm{BA})_{2}(\mathrm{MA})_{2} \mathrm{~Pb}_{3} \mathrm{I}_{10}$-based devices. The Supporting Information is available free of charge on the ACS Publications website at DOI: $10.1021 /$ jacs.5b03796.

\section{AUTHOR INFORMATION}

\section{Corresponding Author}

*m-kanatzidis@northwestern.edu

\section{Notes}

The authors declare no competing financial interest.

\section{ACKNOWLEDGMENTS}

This work was supported as part of the ANSER Center, an Energy Frontier Research Center funded by the U.S. Department of Energy, Office of Science, Office of Basic Energy Sciences, under award number DE-SC0001059. Electron microscopy was performed at EPIC facility (NUANCE Center-Northwestern University). Ultraviolet photoemission spectroscopy was performed at Keck-II facility (NUANCE Center-Northwestern University).

\section{REFERENCES}

(1) Kim, H. S.; Lee, C. R.; Im, J. H.; Lee, K. B.; Moehl, T.; Marchioro, A.; Moon, S. J.; Humphry-Baker, R.; Yum, J. H.; Moser, J. E.; Gratzel, M.; Park, N. G. Sci. Rep. 2012, 2, 591.

(2) Lee, M. M.; Teuscher, J.; Miyasaka, T.; Murakami, T. N.; Snaith, H. J. Science 2012, 338, 643.

(3) Burschka, J.; Pellet, N.; Moon, S. J.; Humphry-Baker, R.; Gao, P.; Nazeeruddin, M. K.; Gratzel, M. Nature 2013, 499, 316.

(4) Jeon, N. J.; Noh, J. H.; Kim, Y. C.; Yang, W. S.; Ryu, S.; Il Seol, S. Nat. Mater. 2014, 13, 897.

(5) Zhou, H. P.; Chen, Q.; Li, G.; Luo, S.; Song, T. B.; Duan, H. S.; Hong, Z. R.; You, J. B.; Liu, Y. S.; Yang, Y. Science 2014, 345, 542.

(6) Jung, H. S.; Park, N. G. Small 2015, 11, 10.

(7) Kojima, A.; Teshima, K.; Shirai, Y.; Miyasaka, T. J. Am. Chem. Soc. 2009, 131, 6050.

(8) Chung, I.; Lee, B.; He, J.; Chang, R. P.; Kanatzidis, M. G. Nature 2012, 485, 486

(9) National Renewable Energy Laboratory, N.R.E.L. http://www. nrel.gov/ncpv/images/efficiency_chart.jpg., (accessed April 12, 2015). 
(10) Mitzi, D. B. Prog. Inorg. Chem. 1999, 48, 1.

(11) Baikie, T.; Fang, Y. N.; Kadro, J. M.; Schreyer, M.; Wei, F. X.; Mhaisalkar, S. G.; Graetzel, M.; White, T. J. J. Mater. Chem. A 2013, 1, 5628.

(12) D’Innocenzo, V.; Grancini, G.; Alcocer, M. J. P.; Kandada, A. R. S.; Stranks, S. D.; Lee, M. M.; Lanzani, G.; Snaith, H. J.; Petrozza, A. Nat. Commun. 2014, 5, 3586.

(13) Hao, F.; Stoumpos, C. C.; Cao, D. H.; Chang, R. P. H.; Kanatzidis, M. G. Nat. Photonics 2014, 8, 489.

(14) Noel, N. K.; Stranks, S. D.; Abate, A.; Wehrenfennig, C.; Guarnera, S.; Haghighirad, A. A.; Sadhanala, A.; Eperon, G. E.; Pathak, S. K.; Johnston, M. B.; Petrozza, A.; Herz, L. M.; Snaith, H. J. Energy Environ. Sci. 2014, 7, 3061.

(15) Ogomi, Y.; Morita, A.; Tsukamoto, S.; Saitho, T.; Fujikawa, N.; Shen, Q.; Toyoda, T.; Yoshino, K.; Pandey, S. S.; Ma, T.; Hayase, S. J. Phys. Chem. Lett. 2014, 5, 1004.

(16) Hao, F.; Stoumpos, C. C.; Chang, R. P.; Kanatzidis, M. G. J. Am. Chem. Soc. 2014, 136, 8094.

(17) Zuo, F.; Williams, S. T.; Liang, P.-W.; Chueh, C.-C.; Liao, C.-Y.; Jen, A. K. Y. Adv. Mater. 2014, 26, 6454.

(18) Smith, I. C.; Hoke, E. T.; Solis-Ibarra, D.; McGehee, M. D.; Karunadasa, H. I. Angew. Chem., Int. Ed. 2014, 53, 11232.

(19) Miller, O. D.; Yablonovitch, E.; Kurtz, S. R. IEEE J. Photovoltaics 2012, 2, 303.

(20) Ishihara, T.; Takahashi, J.; Goto, T. Phys. Rev. B 1990, 42, 11099 .

(21) Mitzi, D. B. Chem. Mater. 1996, 8, 791.

(22) Mitzi, D. B.; Liang, K. Chem. Mater. 1997, 9, 2990.

(23) Kagan, C. R.; Mitzi, D. B.; Dimitrakopoulos, C. D. Science 1999, $286,945$.

(24) Ishihara, T.; Takahashi, J.; Goto, T. Solid State Commun. 1989, 69, 933.

(25) Wu, X. X.; Trinh, M. T.; Niesner, D.; Zhu, H. M.; Norman, Z.; Owen, J. S.; Yaffe, O.; Kudisch, B. J.; Zhu, X. Y. J. Am. Chem. Soc. 2015, 137, 2089.

(26) Calabrese, J.; Jones, N. L.; Harlow, R. L.; Herron, N.; Thorn, D. L.; Wang, Y. J. Am. Chem. Soc. 1991, 113, 2328.

(27) Hong, X.; Ishihara, T.; Nurmikko, A. V. Phys. Rev. B 1992, 45, 6961.

(28) Muljarov, E. A.; Tikhodeev, S. G.; Gippius, N. A.; Ishihara, T. Phys. Rev. B 1995, 51, 14370.

(29) Liu, M.; Johnston, M. B.; Snaith, H. J. Nature 2013, 501, 395.

(30) Chen, Q.; Zhou, H. P.; Hong, Z. R.; Luo, S.; Duan, H. S.; Wang,

H. H.; Liu, Y. S.; Li, G.; Yang, Y. J. Am. Chem. Soc. 2014, 136, 622.

(31) Mitzi, D. B. J. Mater. Chem. 2004, 14, 2355.

(32) Cao, D. H.; Stoumpos, C. C.; Malliakas, C. D.; Katz, M. J.; Farha, O. K.; Hupp, J. T.; Kanatzidis, M. G. APL Mater. 2014, 2, 091101.

(33) Axtell, E. A.; Liao, J. H.; Pikramenou, Z.; Kanatzidis, M. G. Chem.-Eur. J. 1996, 2, 656.

(34) Axtell, E. A.; Park, Y.; Chondroudis, K.; Kanatzidis, M. G. J. Am. Chem. Soc. 1998, 120, 124.

(35) Androulakis, J.; Peter, S. C.; Li, H.; Malliakas, C. D.; Peters, J. A.; Liu, Z. F.; Wessels, B. W.; Song, J. H.; Jin, H.; Freeman, A. J.; Kanatzidis, M. G. Adv. Mater. 2011, 23, 4163.

(36) Stoumpos, C. C.; Malliakas, C. D.; Kanatzidis, M. G. Inorg. Chem. 2013, 52, 9019.

(37) Yamada, Y.; Nakamura, T.; Endo, M.; Wakamiya, A.; Kanemitsu, Y. J. Am. Chem. Soc. 2014, 136, 11610.

(38) Hao, F.; Stoumpos, C. C.; Liu, Z.; Chang, R. P.; Kanatzidis, M. G. J. Am. Chem. Soc. 2014, 136, 16411.

(39) Edri, E.; Kirmayer, S.; Kulbak, M.; Hodes, G.; Cahen, D. J. Phys. Chem. Lett. 2014, 5, 429.

(40) Nayak, P. K.; Cahen, D. Adv. Mater. 2014, 26, 1622.

(41) Xiao, Z.; Yuan, Y.; Shao, Y.; Wang, Q.; Dong, Q.; Bi, C.; Sharma, P.; Gruverman, A.; Huang, J. Nat. Mater. 2014, 14, 193.

(42) Kutes, Y.; Ye, L. H.; Zhou, Y. Y.; Pang, S. P.; Huey, B. D.; Padture, N. P. J. Phys. Chem. Lett. 2014, 5, 3335.
(43) Sanchez, R. S.; Gonzalez-Pedro, V.; Lee, J. W.; Park, N. G.; Kang, Y. S.; Mora-Sero, I.; Bisquert, J. J. Phys. Chem. Lett. 2014, 5, 2357.

(44) Gottesman, R.; Haltzi, E.; Gouda, L.; Tirosh, S.; Bouhadana, Y.; Zaban, A. J. Phys. Chem. Lett. 2014, 5, 2662.

(45) Frost, J. M.; Butler, K. T.; Walsh, A. APL Mater. 2014, 2, 081506.

(46) Kutes, Y.; Ye, L.; Zhou, Y.; Pang, S.; Huey, B. D.; Padture, N. P. J. Phys. Chem. Lett. 2014, 5, 3335.

(47) Kim, H. S.; Park, N. G. J. Phys. Chem. Lett. 2014, 5, 2927.

(48) Nechache, R.; Harnagea, C.; Li, S.; Cardenas, L.; Huang, W.; Chakrabartty, J.; Rosei, F. Nat. Photonics 2015, 9, 61. 